\title{
Dopamine and glutamate receptor genes interactively influence episodic memory in old age
}

\author{
Goran Papenberg a,b,*, Shu-Chen Li $^{\mathrm{a}, \mathrm{c}}$, Irene E. Nagel ${ }^{\mathrm{a}, \mathrm{d}}$, Wilfried Nietfeld ${ }^{\mathrm{e}}$, Brit-Maren Schjeide ${ }^{\mathrm{e}}$, \\ Julia Schröder ${ }^{\mathrm{e}, \mathrm{f}}$, Lars Bertram ${ }^{\mathrm{e}}$, Hauke R. Heekeren ${ }^{\mathrm{a}, \mathrm{d}}$, Ulman Lindenberger ${ }^{\mathrm{a}}$, Lars Bäckman ${ }^{\mathrm{b}}$ \\ ${ }^{a}$ Center for Lifespan Psychology, Max Planck Institute for Human Development, Berlin, Germany \\ ${ }^{\mathrm{b}}$ Aging Research Center, Karolinska Institute and Stockholm University, Stockholm, Sweden \\ ${ }^{c}$ Department of Psychology, Technische Universität Dresden, Dresden, Germany \\ ${ }^{\mathrm{d}}$ Department of Education and Psychology, Freie Universität Berlin, Berlin, Germany \\ e Department of Vertebrate Genomics, Max Planck Institute for Molecular Genetics, Berlin, Germany \\ ${ }^{\mathrm{f}}$ Charité Research Group on Geriatrics, Charité-Universitätsmedizin, Berlin, Germany
}

\section{A R T I C L E I N F O}

\section{Article history:}

Received 11 March 2013

Received in revised form 23 August 2013

Accepted 15 November 2013

Available online 22 November 2013

\section{Keywords:}

Glutamate

Dopamine

Episodic memory

Aging

D2 receptors

NMDA receptors

Gene-gene interactions

\begin{abstract}
A B S T R A C T
Both the dopaminergic and glutamatergic systems modulate episodic memory consolidation. Evidence from animal studies suggests that these two neurotransmitters may interact in influencing memory performance. Given that individual differences in episodic memory are heritable, we investigated whether variations of the dopamine D2 receptor gene (rs6277, C957T) and the N-methyl-D-aspartate 3A (NR3A) gene, coding for the N-methyl-D-aspartate $3 \mathrm{~A}$ subunit of the glutamate $\mathrm{N}$-methyl-D-aspartate receptor (rs10989591, Val362Met), interactively modulate episodic memory in large samples of younger (20-31 years; $n=670)$ and older (59-71 years; $n=832$ ) adults. We found a reliable gene-gene interaction, which was observed in older adults only: older individuals carrying genotypes associated with greater D2 and N-methyl-D-aspartate receptor efficacy showed better episodic performance. These results are in line with findings showing magnification of genetic effects on memory in old age, presumably as a consequence of reduced brain resources. Our findings underscore the need for investigating interactive effects of multiple genes to understand individual difference in episodic memory.
\end{abstract}

(c) 2014 Elsevier Inc. All rights reserved.

\section{Introduction}

Episodic memory is a heritable (e.g., McClearn et al., 1997) and polygenic (Papassotiropoulos and de Quervain, 2011) trait. We explore whether genetic predispositions of dopaminergic and glutamatergic neuromodulation interactively influence episodic memory in younger and older adults. Given increased heterogeneity of episodic memory in old age (e.g., de Frias et al., 2007), we are particularly interested in whether genetic effects are stronger in older than in younger adults.

\subsection{Dopaminergic modulation of episodic memory}

A large number of animal studies indicates that memory performance is impaired when dopamine (DA) receptors are blocked and enhanced when DA agonists are injected in hippocampus (for review, see Lisman and Grace, 2005). DA prolongs long-term

\footnotetext{
* Corresponding author at: Aging Research Center, Gävlegatan 16, SE-113 30 Stockholm, Sweden. Tel.: +467869058 75; fax: +467869068 89 .

E-mail address: goran.papenberg@ki.se (G. Papenberg).
}

potentiation (LTP; Frey et al., 1990, 1993; Huang and Kandel, 1995), a cellular mechanism necessary for successful memory formation and consolidation (for review, see Cooke and Bliss, 2006). In humans, molecular imaging studies have related higher D2 receptor binding in hippocampus to better recall of verbal (Takahashi et al., 2007) and pictorial (Takahashi et al., 2008) memory. Relatedly, striatal D2 receptor density has been associated with better performance across different episodic memory tasks (Bäckman et al., 2000; Cervenka et al., 2008).

\subsection{Glutamatergic modulation of episodic memory}

Animal and human data further suggest that glutamate also modulates episodic memory. In particular, N-methyl-D-aspartate (NMDA) receptors play a crucial role in learning and memory formation (for review, see Rezvani, 2006). Animal data show that activation of NMDA receptors is required for LTP in hippocampus (e.g., Izquierdo, 1994). In particular, NMDA receptors seem to be more critical for encoding and consolidation than for retrieval of episodic memories (e.g., Day et al., 2003; Matus-Amat et al., 2007). 
Human evidence indicates that pharmacologic blockade of NMDA receptors impairs learning and memory (Morgan et al., 2004; Rockstroh et al., 1996), whereas post-learning administration of an NMDA agonist facilitates consolidation of fearful memories (Kalisch et al., 2009).

\subsection{Interactive effects of DA and glutamate on episodic memory}

Computational simulations suggest that dopaminergic modulation stabilizes NMDA currents, resulting in sharpened memory representations (e.g., Durstewitz et al., 1999, 2000). Other than their separate effects, animal research also suggests that the DA and glutamate systems may interact in influencing memory performance (Adriani et al., 1998; Cestari and Castellano, 1997; Ferretti et al., 2005; Mele et al., 1996). For instance, Cestari and Castellano (1997) reported that impairment of memory consolidation by blocking NMDA receptors is potentiated by simultaneous blockade of DA receptors. Similarly, memory impairment induced by an NMDA receptor antagonist is attenuated by low doses of DA receptor agonists (Mele et al., 1996). These patterns of interactions may reflect DA-induced facilitation of NMDA receptor-dependent LTP in hippocampus (e.g., Hansen and Manahan-Vaughan, 2012; Roggenhofer et al., 2010).

\subsection{Study aims and hypotheses}

Thus far, human studies investigating interactive influences of DA and NMDA modulation of episodic memory are lacking. We therefore examined the effects of the DA D2 gene (DRD2) and the NR3A gene, coding for the N-methyl-D-aspartate 3A (NR3A) subunit of the glutamate NMDA receptor, on episodic memory in young and old adults. Carriers of the DRD2 C/C genotype have higher D2 receptor densities in neocortical and limbic regions, including the hippocampus (Hirvonen et al., 2009). The DRD2 C/C genotype has also been associated with better backward serial memory, particularly in older adults (Li et al., 2013). Less is known about the NR3A gene. An electroencephalographic study reported that the NR3AT/T genotype is associated with better prefrontal information processing (Gallinat et al., 2007), presumably reflecting higher NMDA receptor efficacy. Relative to carriers of the NR3A T/T genotype, C/C homozygotes showed reduced frontal P300 amplitudes during an auditory oddball task.

Given the role of DA and glutamate in modulating episodic memory and their potential interaction, we expected that individuals with genetic predispositions for both higher receptor efficacy with respect to D2 (i.e., DRD2 C/C) and NMDA (i.e., NR3A T/T) receptors would show better episodic memory performance than those carrying fewer advantageous genotypes. We tested this hypothesis using an item and associative recognition memory task (Naveh-Benjamin, 2000; Naveh-Benjamin et al., 2003). Further, the resource modulation hypothesis predicts magnified genetic effects in populations with lower structural and neurochemical brain resources (Lindenberger et al., 2008). Thus, we expected that the 2 polymorphisms would modulate episodic memory to a greater extent in older than in younger adults.

\section{Methods}

\subsection{Participants}

A total number of 788 young (20-31 years; $52.2 \%$ female) and 1222 old (59-71 years; $60.5 \%$ female) adults were recruited via newspaper announcements and advertisements in public transportation. All participants reported normal or corrected to normal vision, were right-handed, as indexed by the Edinburgh
Handedness Index (Oldfield, 1971), and had completed at least 8 years of education. Older participants scored over 27 on the Mini Mental State Examination. No participant was on medications that may affect memory, and none reported a history of head injury, medical (e.g., heart attack), neurologic (e.g., epilepsy), or psychiatric (e.g., depression) disease.

\subsection{Genotyping}

DNA was extracted from peripheral blood using standard methods. The polymorphisms of the DRD2 (C957T, rs6277) and the NR3A gene (Val362Met, rs10989591) were genotyped using the commercially available TaqMan Open Array multiplex genotyping system (C_11339240_10 for rs6277 and C_1792848_10 for rs10989591; TaqMan Open Array Genotyping Plate; Applied Biosystems, Forster City, CA, USA), following established procedures (Schjeide et al., 2011). The genotype frequencies in younger adults were: DRD2-160:399:229 (C/C:C/T:T/T) and NR3A-84:348:356 (T/ $\mathrm{T}: \mathrm{C} / \mathrm{T}: \mathrm{C} / \mathrm{C})$. The corresponding distributions for the older sample were DRD2-278:591:353 (C/C:C/T:T/T) and NR3A-145:568:509 (T/ $\mathrm{T}: \mathrm{C} / \mathrm{T}: \mathrm{C} / \mathrm{C})$. In both age groups, both polymorphisms were in Hardy-Weinberg equilibrium ( $p s>0.05$ ).

\subsection{Experimental task}

Participants underwent two cognitive testing sessions one week apart. Each session lasted about 3 hours and participants were tested in groups of six individuals of the same age. The cognitive battery assessed episodic memory, working memory, executive functioning, perceptual speed, and psychometric intelligence. Responses were made via button boxes and keyboards. The episodic memory task of interest in this study is described in the following.

We used an item and associative recognition memory task (Naveh-Benjamin, 2000). The task involved 4 different conditions. During the study phase, 30 word pairs were presented sequentially for 6 seconds in each condition. The pairs consisted of semantically unrelated German nouns. Participants were instructed to study the items either as 2 single words (item instruction) or as a pair of words (pair instruction). Following study, participants had to count backwards in steps of 3 (i.e., 335-332-329) for 90 seconds to prevent rehearsal and minimize the influence of short-term memory. Then the test phase followed with either an item or an associative recognition test. In the item conditions, participants decided whether or not a word had been presented during study. Half of the presented words were old, and the other half was new. In the associative conditions, participants indicated whether or not a word pair had been presented at study phase. Half of the pairs were old, and the other half consisted of pairs formed by recombining words in the previously studied list of pairs. In recognition, 30 words or word pairs were presented for 4 seconds each. The combination of the 2 factors, study instruction and recognition test, resulted in 4 different conditions: (1) item instruction-item test, (2) pair instruction-item test, (3) item instruction-associative test, and (4) pair instruction-associative test.

\subsection{Data-based exclusion criteria}

Participants with negative hits minus false alarms or more than $20 \%$ non-responses in any of the conditions were excluded from analyses (15\% of younger adults and $30 \%$ of older adults), because this indicates that the task was not performed appropriately. In the total sample, the gene-gene interaction remained reliable in older adults $(\mathrm{n}=1222)$, as reported in the following. The relative proportion of excluded subjects did not differ across the 4 genotype groups ( $p s>0.10$ in both younger and older adults). The final 
Table 1

Demographic variables and self-reported health across age, NR3A and DRD2 genotype groups

\begin{tabular}{|c|c|c|c|c|}
\hline \multirow[t]{4}{*}{ DRD2 genotype } & \multicolumn{4}{|c|}{ Younger adults $(n=670)$} \\
\hline & \multicolumn{2}{|c|}{ NR3A any $C$} & \multicolumn{2}{|l|}{ NR3A T/T } \\
\hline & Any $\mathrm{T}$ & $\mathrm{C} / \mathrm{C}$ & Any $\mathrm{T}$ & $\mathrm{C} / \mathrm{C}$ \\
\hline & $\mathrm{n}=477$ & $\mathrm{n}=124$ & $\mathrm{n}=54$ & $\mathrm{n}=15$ \\
\hline \multicolumn{5}{|l|}{ Demographics } \\
\hline Age $(M \pm S D)$ & $26.0(2.9)$ & $26.1(2.9)^{a}$ & $26.3(2.5)$ & $25.4(2.6)^{\mathrm{a}}$ \\
\hline Women/Men & $268 / 209$ & $66 / 58^{b}$ & $31 / 23$ & $7 / 8^{\mathrm{b}}$ \\
\hline Years of education $(\mathrm{M} \pm \mathrm{SD})$ & $12.6(1.1)$ & $12.8(1.3)^{\mathrm{a}}$ & $12.2(1.4)$ & $12.5(1.3)^{\mathrm{a}}$ \\
\hline State of health $(\mathrm{M} \pm \mathrm{SD})$ & $4.2(0.6)$ & $4.2(0.7)^{\mathrm{a}}$ & $4.2(0.6)$ & $4.1(0.5)^{\mathrm{a}}$ \\
\hline \multirow[t]{4}{*}{ DRD2 genotype } & \multicolumn{4}{|c|}{ Older adults $(\mathrm{n}=832)$} \\
\hline & \multicolumn{2}{|c|}{ NR3A any $C$} & \multicolumn{2}{|l|}{ NR3A T/T } \\
\hline & Any $\mathrm{T}$ & $\mathrm{C} / \mathrm{C}$ & Any $\mathrm{T}$ & $\mathrm{C} / \mathrm{C}$ \\
\hline & $\mathrm{n}=564$ & $\mathrm{n}=172$ & $\mathrm{n}=72$ & $\mathrm{n}=24$ \\
\hline Age $(\mathrm{M} \pm \mathrm{SD})$ & $65.0(2.8)$ & $65.1(2.9)^{\mathrm{a}}$ & $65.0(3.1)$ & $64.6(2.9)^{\mathrm{a}}$ \\
\hline Women/Men & $352 / 212$ & $96 / 76^{\mathrm{b}}$ & $48 / 24$ & $14 / 10^{\mathrm{b}}$ \\
\hline Years of education $(\mathrm{M} \pm \mathrm{SD})$ & $10.9(1.8)$ & $10.8(1.6)^{\mathrm{a}}$ & $10.8(1.5)$ & $11.0(1.6)^{\mathrm{a}}$ \\
\hline State of health $(\mathrm{M} \pm \mathrm{SD})$ & $4.0(0.6)$ & $3.9(0.6)^{a}$ & $3.9(0.6)$ & $4.2(0.6)^{\mathrm{a}}$ \\
\hline
\end{tabular}

State of health is based on the mean of four self-ratings on 5 -point scales ( $1=$ poor; $5=$ excellent).

Key: DRD2, dopamine D2 receptor; NR3A, N-methyl-D-aspartate receptor subunit $3 \mathrm{~A}$

a One-way analyses of variance $=$ n.s.

b $\chi^{2}=$ n.s.

effective sample included 670 younger and 832 older adults. Table 1 presents demographics and self-reported health data across age, DRD2, and NR3A genotype groups. Importantly, the 4 genotype groups did not differ with respect to demographic and self-reported health data in either age group.

\subsection{Statistical analyses}

Behavioral and demographic data were analyzed using SPSS for Windows 15.0 (SPSS, Chicago, IL, USA). We conducted a repeatedmeasures analysis of covariance with study instruction (item, pair) and recognition test (item, associative) as dependent variables and NR3A gene (any C, T/T), DRD2 gene (any T, C/C), and age group (young, old) as between-subjects variables. Following Li et al. (2013), participants carrying the advantageous genotype for both genes were contrasted against those who did not. Given female superiority in episodic memory (Herlitz et al., 1997), sex was included as a covariate in the analyses. For all analyses, the alpha level was set at $p=0.05$. Effect sizes are indicated by partial eta squared $\left(\eta^{2}\right)$.

\section{Results}

We found significant main effects for study instruction, $F(1,1493)=12.05, \eta^{2}=0.008$, and recognition test, $F(1,1493)=$ $56.72, \eta_{p}^{2}=0.037$, reflecting worse performance when item instructions were given during encoding and when pairs needed to be recognized during retrieval. The interaction between study instruction and recognition test was also significant, $F(1,1493)=$ $31.00, \eta_{p}^{2}=0.020$, indicating the lowest performance in both age groups when item encoding was combined with associative retrieval. In addition, the main effect of age group was significant, $F(1,1493)=60.79, \eta_{\mathrm{p}}^{2}=0.039$, with older adults performing worse than younger adults. There were reliable interactions of study instruction $\times$ age group, $F(1,1493)=14.32, \eta_{p}^{2}=0.009$, and of recognition test $\times$ age group, $F(1,1493)=4.74, \eta^{2}=0.003$, indicating that the effects of both experimental manipulations were more pronounced in older adults. Further, the triple interaction among study instruction $\times$ recognition test $\times$ age group was reliable, $F(1,1493)=5.18, \eta^{2} \mathrm{p}=0.003$, reflecting that older adults were particularly disadvantaged when items were learned, but word pairs had to be recognized.

With respect to genetic influences, there was no main effect of either gene $(p>0.1)$. However, we observed a reliable NR3A $\times$ DRD2 $\times$ age group interaction, $F(1,1493)=4.03, \eta_{p}^{2}=0.003$, reflecting that interactive genetic effects were observed in older adults only. To trace the source of the NR3A $\times$ DRD2 $\times$ age group interaction, a series of $t$ tests was carried out. Older adults who carry both the DRD2 C/C and the NR3A T/T genotype outperformed all other older genotype groups (compared with DRD2 any T and NR3A any $C, t(586)=-3.44$; compared with DRD2 C/C and NR3A Any C, $t(194)=-3.26$, compared with DRD2 any T and NR3 A T/T, $t$ $(94)=-2.51)$. For the young, the 4-genotype groups did not differ with respect to overall memory performance $(p>0.10)$.

The triple interaction of recognition test $\times$ NR3A $\times$ age group was also significant, $F(1,1493)=3.92, \eta^{2} p=0.003$. Similarly, the 4 -way interaction of recognition test $\times \mathrm{NR} 3 \mathrm{~A} \times \mathrm{DRD} 2 \times$ age group was reliable, $F(1,1493)=4.66, \eta^{2}=0.003$. Bar graphs in Fig. 1 portray proportion of hits minus false alarms as a function of recognition test, NR3A genotype, and DRD2 genotype in the 2 age groups. We conducted an additional analysis of covariance in older adults to probe whether interactions between genes and recognition test would remain significant or whether they are also driven by the slightly lower performance in associative memory in younger adults with DRD2 C/C and NR3A T/T genotypes (see Fig. 1). These analyses revealed main effects of DRD2, $F(1,827)=5.10$, $\eta_{\mathrm{p}}^{2}=0.006$, and NR3A, $F(1,827)=6.03, \eta_{\mathrm{p}}^{2}=0.007$, as well as a reliable NR3A $\times$ DRD2 interaction, $F(1,827)=3.90, \eta_{p}^{2}=0.004$. Interactive effects between genes and recognition test were not reliable $(p>0.1)$, suggesting that genetic effects were comparable in both item and associative memory for older adults.

A second set of control analyses was conducted. Given the small sample sizes in the 2 critical groups (i.e., younger and older DRD2 C/C and NR3A T/T carriers), we performed bootstrap analyses to control and check the stability of results. Thus, we generated sample-based confidence intervals (CIs) around the means that confirm the gene-gene interaction in older adults. Specifically, we examined 10,000 samples with replacement from the original data set, keeping the same number of participants present in each of the 8 groups. To construct $95 \%$ CIs, we used the 2.5 and 97.5 percentiles from the bootstrap distribution. The analyses are based on a composite score of all 4 experimental conditions. In line with the results from the analysis of covariance, the CIs around the means in younger adults overlap for all 4 groups (DRD2 any T and NR3A any C: $95 \% \mathrm{CI}$ [0.59-0.61]; DRD2 C/C and NR3A any C: 95\% CI [0.61-0.64]; DRD2 any T and NR3A T/T: 95\% CI [0.60-0.65]; DRD2 C/C and NR3A T/T: $95 \% \mathrm{CI}[0.55-0.63])$, indicating no differences among groups. However, in older adults, the $\mathrm{CI}$ around the mean for the group carrying the 2 beneficial DRD2 C/C and NR3A T/T genotypes (95\% CI [0.52-0.59]) does not overlap with the CIs around the means for the other 3 genotype groups (DRD2 any $\mathrm{T}$ and NR3A any $\mathrm{C}$ : $95 \% \mathrm{CI}$ [0.46-0.47]; DRD2 C/C and NR3A any C: 95\% CI [0.46-0.48]; DRD2 any T and NR3A T/T: 95\% CI [0.46-0.50]). Indeed, the CIs for the latter 3 groups were almost identical. Thus, the bootstrap analyses confirm the pattern obtained in the analyses reported previously.

\section{Discussion}

Given previously reported interactive effects of DA and glutamate on episodic memory in animal studies (e.g., Cestari and Castellano, 1997; Ferretti et al., 2005; Mele et al., 1996), we investigated whether genetic predispositions, associated with DA D2 and glutamate NMDA receptors, would interactively influence episodic performance in humans. In addition, we examined whether 
Item Recognition

Associative Recognition

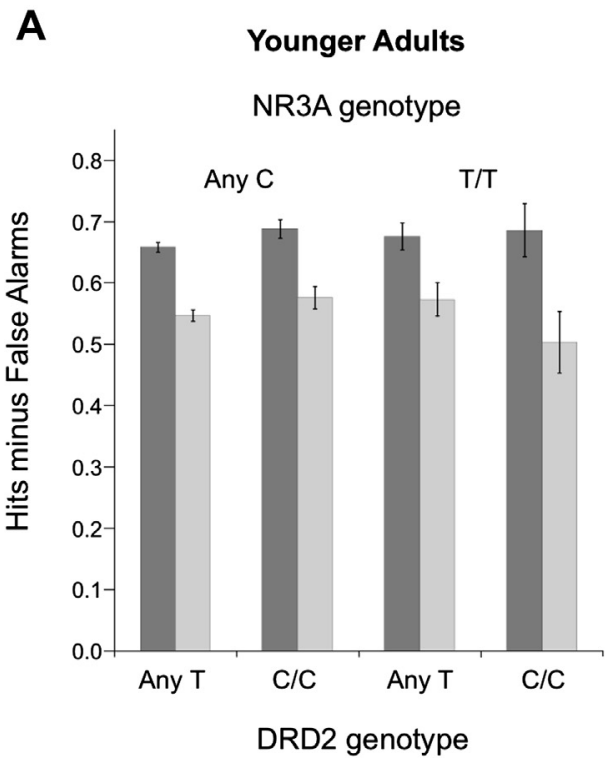

B Older Adults

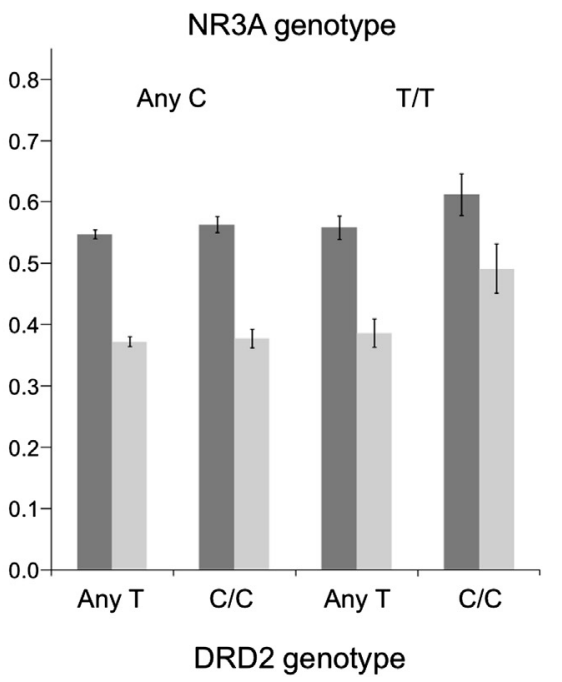

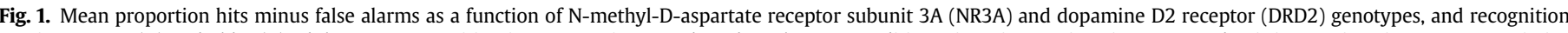

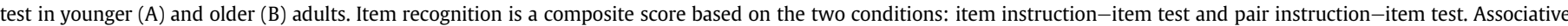

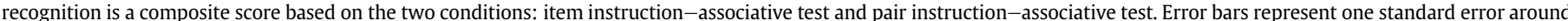
the means. Abbreviations: DRD2, dopamine D2 receptor; NR3A, N-methyl-D-aspartate receptor subunit 3A.

potential genotype effects would be stronger in older than in younger adults, as postulated by the resource modulation hypothesis (Lindenberger et al., 2008).

Older carriers of genotypes associated with higher hippocampal D2 receptor densities (the DRD2 C/C genotype) and greater NMDA efficacy (the NR3A T/T genotype) showed reduced age-related episodic memory deficits relative to the other genotype groups. Notably, advantageous effects of the two genes were also present in more demanding associative memory conditions, in which older adults showed stronger impairments corroborating the wellestablished associative-memory deficit in aging (e.g., NavehBenjamin, 2000; Shing et al., 2008). In younger adults, genetic effects did not differ reliably from zero and were reliably smaller than in older adults. This pattern of age differences provides further support for the resource modulation hypothesis, which posits that effects of common genetic polymorphisms on cognition are stronger in populations with reduced brain resources, such as older adults (Lindenberger et al., 2008). Healthy aging is associated with marked decline in dopaminergic neuromodulation (Bäckman et al., 2006, 2010). Similarly, NMDA receptor efficacy declines with advancing adult age, as documented in both animal and human studies (for a review, see Magnusson et al., 2010). We recently reported that the DRD2 C/C genotype was associated with better backward serial recall. The DRD2 gene interacted with a polymorphism coding for the DA transporter (DAT), with magnified effects in old age (Li et al., 2013). Similar to the present findings, older carriers with two beneficial genotypes, associated with greater striatal DA availability and higher hippocampal D2 receptor density, performed particularly well. In another study, genetic predispositions for DA-relevant genes affecting DAT expression and D2-like receptors (i.e., D2 and D3) were aggregated into a composite genetic score (Papenberg et al., 2013). Older adults carrying more beneficial alleles showed an episodic memory advantage, this time in terms of less forgetting of pictorial materials; no genetic effects were found in younger adults. The present findings extend previous observations by demonstrating gene-gene interactions across different transmitter systems on episodic memory. In agreement with the study by Gallinat et al. (2007), the NR3A T/T genotype was beneficial in our study. However, replication of the NR3A effect and its interaction with the DRD2 gene in independent samples is necessary to substantiate the current observations. Other than episodic memory, it is of note that empirical support for the resource modulation hypothesis has also been reported for inhibitory control (Colzato et al., 2013) and reinforcement learning (Hämmerer et al., 2013).

Based on animal evidence, Lisman and Grace (2005) proposed that the dopaminergic midbrain and hippocampus form a functional loop, controlling the formation of long-term episodic memories. According to this model, hippocampus detects a novelty signal, which is not stored in long-term memory. This signal is transmitted to the ventral tegmental area, where it enhances novelty-related activity of dopaminergic neurons. Consequently, DA is released in hippocampus, resulting in an enhancement of plasticity-related molecular mechanisms, such as LTP. In humans, imaging studies have supported this model by reporting that coactivation of dopaminergic midbrain regions and hippocampus during episodic encoding is associated with enhanced long-term memory of previously rewarded stimuli (Adcock et al., 2006; Wittmann et al., 2005).

The NR3A subunit of the NMDA receptor is involved in regulating NMDA receptor function (Roberts et al., 2009). In animal studies, prolonged NR3A expression has been associated with impairments in learning and memory processes because of deficits in hippocampal LTP. Thus, downregulation of the NR3A-containing NMDA receptors is required for memory consolidation (Roberts et al., 2009). T/T carriers of the NR3A gene might have lower expression of NR3A resulting in stronger NMDA currents, with beneficial effects on memory consolidation. These effects may be potentiated by inputs from the dopaminergic systems, particularly in older individuals with the DRD2 C/C genotype. That said, the exact molecular mechanisms underlying the interaction of the 
DRD2 and NR3A polymorphisms in episodic memory remain to be elucidated.

In conclusion, we report that the DRD2 and NR3A genes exert interactive effects on episodic memory performance in older adults, contributing to the commonly observed increased interindividual cognitive variation in old age (de Frias et al., 2007; Rönnlund et al., 2005). To our knowledge, this is the first evidence of interactive effects between genes related to the DA and glutamate systems on human episodic memory. Our results are in line with recent studies showing magnification of genetic effects on cognition in old age (Colzato et al., 2013; Li et al., 2010a, 2010b, 2013; Papenberg et al., 2013). The current findings underscore the need to investigate interactive effects of multiple genes to understand interindividual differences in episodic memory in adulthood and aging.

\section{Disclosure statement}

The authors disclose that there are no conflicts of interest. Participants gave informed consent and were paid $€ 7$ per hour for their participation. The ethics committee of the Charite Universitätsmedizin Berlin approved the study.

\section{Acknowledgements}

This research was supported by the Max Planck Society, including grants from the innovation fund of the Max Planck Society (M.FE.Abild0006). It was also supported by a grant from the German Federal Ministry of Education and Research to the Berlin NeuroImaging Center (01G00501). Lars Bäckman was supported by the Swedish Research Council, Swedish Brain Power, an Alexander von Humboldt Research Award, and a donation from the af Jochnick Foundation. The authors thank Kirsten Becker, Ludmila Müller, Carolin Stockmeyer, and the other research assistants for their help.

\section{References}

Adcock, R.A., Thangavel, A., Whitfield-Gabrieli, S., Knutson, B., Gabrieli, J.D.E., 2006. Reward-motivated learning: mesolimbic activation precedes memory formation. Neuron 50, 507-517.

Adriani, W., Felici, A., Sargolini, F., Roullet, P. Usiello, A., Oliverio, A. Mele, A. 1998. $\mathrm{N}$-methyl-D-aspartate and dopamine receptor involvement in the modulation of locomotor activity and memory processes. Exp. Brain Res. 123, 52-59.

Bäckman, L., Lindenberger, U., Li, S.-C., Nyberg, L., 2010. Linking cognitive aging to alterations in dopamine neurotransmitter functioning: recent data and future avenues. Neurosci. Biobehav. Rev. 34, 670-677.

Bäckman, L., Nyberg, L., Lindenberger, U., Li, S.-C., Farde, L., 2006. The correlative triad among aging, dopamine, and cognition: current status and future prospects. Neurosci. Biobehav. Rev. 30, 791-807.

Bäckman, L., Ginovart, N., Dixon, R.A., Wahlin, T.B., Wahlin, A., Halldin, C., Frade, L., 2000. Age-related cognitive deficits mediated by changes in the striatal dopamine system. Am. J. Psychiatry 157, 635-637.

Cervenka, S., Bäckman, L., Cselényi, Z., Halldin, C., Farde, L., 2008. Associations between dopamine D2-receptor binding and cognitive performance indicate functional compartmentalization of the human striatum. Neuroimage 40, $1287-1295$.

Cestari, V., Castellano, C., 1997. MK-801 potentiates morphine-induced impairment of memory consolidation in mice: involvement of dopaminergic mechanisms. Psychopharmacology (Berl) 133, 1-6.

Colzato, L.S., van den Wildenberg, W.P., Hommel, B., 2013. The genetic impact (C957T-DRD2) on inhibitory control is magnified by aging. Neuropsychologia 51, 1377-1381.

Cooke, S.F., Bliss, T.V., 2006. Plasticity in the human central nervous system. Brain 129, 1659-1673.

Day, M., Langston, R., Morris, R.G., 2003. Glutamate-receptor-mediated encoding and retrieval of paired-associate learning. Nature 424, 205-209.

Durstewitz, D., Kelc, M., Güntürkün, O., 1999. A neurocomputational theory of the dopaminergic modulation of working memory functions. J. Neurosci. 19, 2807-2822.

Durstewitz, D., Seamans, J.K., Sejnowski, T.J., 2000. Dopamine-mediated stabilization of delayed-period activity in a network model of prefrontal cortex. J. Neurophysiol. 83, 1733-1750.

de Frias, M., Lövdén, C.M., Lindenberger, U., Nilsson, L.-G., 2007. Revisiting the dedifferentiation hypothesis with longitudinal multi-cohort data. Intelligence 35, 381-392.
Ferretti, V., Florian, C., Costantini, V.J., Roullet, P., Rinaldi, A., De Leonibus, E. Oliverio, A., Mele, A., 2005. Co-activation of glutamate and dopamine receptors within the nucleus accumbens is required for spatial memory consolidation in mice. Psychopharmacology (Berl) 179, 108-116.

Frey, U., Huang, Y.-Y., Kandel, E.R., 1993. Effects of cAMP simulate a late stage of LTP in hippocampal CA1 neurons. Science 260, 1661-1664.

Frey, U., Schroeder, H., Matthies, H., 1990. Dopaminergic antagonists prevent longterm maintenance of posttetanic LTP in the CA1 region of rat hippocampal slices. Brain Res. 522, 69-75.

Gallinat, J., Gotz, T., Kalus, P., Bajbouj, M., Sander, T., Winterer, G., 2007. Genetic variations of the NR3A subunit of the NMDA receptor modulate prefrontal cerebral activity in humans. J. Cogn. Neurosci. 19, 59-68.

Hansen, N., Manahan-Vaughan, D., 2012. Dopamine D1/D5 receptors mediate informational saliency that promotes persistent hippocampal long-term plasticity. Cereb. Cortex.

Hämmerer, D., Biele, G., Müller, V., Thiele, H., Nürnberg, P., Heekeren, H. R., Li, S.-C., 2013. Effects of PPP1R1B (DARPP-32) polymorphism on feedback-related brain potentials across the lifespan. Front. Psychol. 4.

Herlitz, A., Nilsson, L.G., Bäckman, L., 1997. Gender differences in episodic memory. Mem. Cognit 25, 801-811.

Hirvonen, M., Lumme, V., Hirvonen, J., Pesonen, U., Någren, K., Vahlberg, T. Scheinin, H., Hietala, J., 2009. C957T polymorphism of the human dopamine D2 receptor gene predicts extrastriatal dopamine receptor availability in vivo. Prog Neuropsychopharmacol. Biol. Psychiatry 33, 630-636.

Huang, Y.-Y., Kandel, E.R., 1995. D1/D5 receptor agonists induce a protein synthesisdependent late potentiation in the CA1 region of the hippocampus. Proc. Natl. Acad. Sci. U S A 92, 2446-2450.

Izquierdo, I., 1994. Pharmacological evidence for a role of long-term potentiation in memory. FASEB J. 8, 1139-1145.

Kalisch, R., Holt, B., Petrovic, P., De Martino, B., Kloppel, S., Buchel, C., Dolan, R.J., 2009. The NMDA agonist D-cycloserine facilitates fear memory consolidation in humans. Cereb. Cortex 19, 187-196.

Li, S.-C., Chicherio, C., Nyberg, L., von Oertzen, T., Nagel, I.E., Papenberg, G., Sander, T. Heekeren, H.R., Lindenberger, U., Bäckman, L., 2010a. Ebbinghaus revisited: influences of the BDNF Val66Met polymorphism on backward serial recall are modulated by human aging. J. Cogn. Neurosci. 22, 2164-2173.

Li, S.-C., Lindenberger, U., Bäckman, L., 2010b. Dopaminergic modulation of cognition across the lifespan. Neurosci. Biobehav. Rev. 34, 625-630.

Li, S.-C., Papenberg, G., Nagel, I.E., Preuschhof, C., Schröder, J., Nietfeld, W. Bertram, L., Heekeren, H.R., Lindenberger, U., Bäckman, L., 2013. Aging magnifies the effects of dopamine transporter and D2 receptor genes on backward serial memory. Neurobiol. Aging 34, 358.e1-358.e10.

Lindenberger, U., Nagel, I.E., Chicherio, C., Li, S.C., Heekeren, H.R., Bäckman, L., 2008 Age-related decline in brain resources modulates genetic effects on cognitive functioning. Front. Neurosci. 2, 234-244.

Lisman, J.E., Grace, A.A., 2005. The hippocampal-VTA loop: controlling the entry of information into long-term memory. Neuron 46, 703-713.

Magnusson, K.R., Brim, B.L., Das, S.R., 2010. Selective vulnerabilities of N-methylD-aspartate (NMDA) receptors during brain aging. Front. Aging Neurosci. 2, 11

Matus-Amat, P., Higgins, E.A., Sprunger, D., Wright-Hardesty, K., Rudy, J.W., 2007. The role of dorsal hippocampus and basolateral amygdala NMDA receptors in the acquisition and retrieval of context and contextual fear memories. Behav. Neurosci. 121, 721-731.

McClearn, G.E., Johansson, B., Berg, S., Pedersen, N.L., Ahern, F., Petrill, S.A. Plomin, R., 1997. Substantial genetic influence on cognitive abilities in twins 80 or more years old. Science 276, 1560-1563.

Mele, A., Castellano, C., Felici, A., Cabib, S., Caccia, S., Oliverio, A., 1996. Dopamine$\mathrm{N}$-methyl-D-aspartate interactions in the modulation of locomotor activity and memory consolidation in mice. Eur. J. Pharmacol. 308, 1-12.

Morgan, C.J., Mofeez, A., Brandner, B., Bromley, L., Curran, H.V., 2004. Acute effects of ketamine on memory systems and psychotic symptoms in healthy volunteers Neuropsychopharmacology 29, 208-218.

Naveh-Benjamin, M., 2000. Adult age differences in memory performance: tests of an associative deficit hypothesis. J. Exp. Psychol. Learn Mem. Cogn. 26 $1170-1187$.

Naveh-Benjamin, M., Hussain, Z., Guez, J., Bar-On, M., 2003. Adult age differences in episodic memory: further support for an associativedeficit hypothesis. J. Exp. Psychol. Learn Mem. Cogn. 29, 826-837.

Oldfield, R.C., 1971. The assessment and analysis of handedness: the Edinburgh inventory. Neuropsychologia 9, 97-113.

Papassotiropoulos, A., de Quervain, D.J.F., 2011. Genetics of human episodic memory: dealing with complexity. Trends Cogn. Sci. 15, 381-387.

Papenberg, G., Bäckman, L., Nagel, I.E., Nietfeld, W., Schröder, J., Bertram, L., Heekeren, H.R., Lindenberger, U., Li, S.C., 2013. Dopaminergic gene polymorphisms affect long-term forgetting in old age: further support for the magnification hypothesis. J. Cogn. Neurosci. 25, 571-579.

Rezvani, A.H., 2006. Involvement of the NMDA system in learning and memory. In: Levin, E.D., Buccafusco, J.J. (Eds.), Animal Models of Cognitive Impairment. CRC Press, Boca Raton (FL).

Roberts, A.C., Diez-Garcia, J., Rodriguiz, R.M., Lopez, I.P., Lujan, R., MartinezTurrillas, R., Picó, E., Henson, M.A., Bernardo, D.R., Jarrett, T.M., Clendeninn, D.J., López-Mascaraque, L., Feng, G., Lo, D.C., Wesseling, J.F., Wetsel, W.C. Philpot, B.D., Pérez-Otaño, I., 2009. Downregulation of NR3A-containing NMDARs is required for synapse maturation and memory consolidation. Neuron 63, 342-356. 
Rockstroh, S., Emre, M., Tarral, A., Pokorny, R., 1996. Effects of the novel NMDAreceptor antagonist SDZ EAA 494 on memory and attention in humans. Psychopharmacology (Berl) 124, 261-266.

Roggenhofer, E., Fidzinski, P., Bartsch, J., Kurz, F., Shor, O., Behr, J., 2010. Activation of dopamine D1/D5 receptors facilitates the induction of presynaptic long-term potentiation at hippocampal output synapses. Eur. J. Neurosci. 32, 598-605.

Rönnlund, M., Nyberg, L., Bäckman, L., Nilsson, L.G., 2005. Stability, growth, and decline in adult life span development of declarative memory: cross-sectional and longitudinal data from a population-based study. Psychol. Aging 20, 3-18.

Shing, Y.L., Werkle-Bergner, M., Li, S.-C., Lindenberger, U., 2008. Associative and strategic components of episodic memory: a lifespan dissociation. J. Exp. Psychol. Gen. 137, 495-513.

Schjeide, B.-M.M., Schnack, C., Lambert, J.-C., Lill, C.M., Kirchheiner, J., Tumani, H., Otto, M., Tanzi, R.E., Lehrach, H., Amouyel, P., von Arnim, C.A.F., Bertram, L., 2011.
The role of clusterin, complement receptor 1, and phosphatidylinositol binding clathrin assembly protein in Alzheimer disease risk and cerebrospinal fluid biomarker levels. Arch. Gen. Psychiatry 68, 207-213.

Takahashi, H., Kato, M., Hayashi, M., Okubo, Y., Takano, A., Ito, H., Suhara, T., 2007 Memory and frontal lobe functions; possible relations with dopamine D2 receptors in the hippocampus. Neuroimage 34, 1643-1649.

Takahashi, H., Kato, M., Takano, H., Arakawa, R., Okumura, M., Otsuka, T., Kodaka, F. Hayashi, M., Okubo, Y., Ito, H., Suhara, T., 2008. Differential contributions of prefrontal and hippocampal dopamine $\mathrm{D}(1)$ and $\mathrm{D}(2)$ receptors in human cognitive functions. J. Neurosci. 28, 12032-12038.

Wittmann, B.C., Schott, B.H., Guderian, S., Frey, J.U., Heinze, H.-J., Düzel, E., 2005. Reward-related FMRI activation of dopaminergic midbrain is associated with enhanced hippocampus-dependent long-term memory formation. Neuron 45, 459-467. 